\title{
A GUARDA COMPARTILHADA E SEUS ASPECTOS RELEVANTES
}

\author{
Carla Eduarda de Oliveira Pirondi, Luciana Claudia Silva Lima \\ Universidade do Oeste Paulista - UNOESTE, curso de Direito, Presidente Prudente, SP. E-mail: \\ carla_eduardapirondi@hotmail.com
}

\section{RESUMO}

Esta obra visou fazer considerações a respeito da guarda compartilhada, trazendo os temas que a interligam e que são de suma importância para a melhor compreensão do instituto. A guarda compartilhada é uma modalidade de guarda que foi instituída em nosso ordenamento jurídico com a finalidade de assegurar a dupla participação dos pais na criação dos filhos e com os deveres a eles inerentes. A realização desse estudo torna-se perfeitamente cabível, ao passo de que é um fato vivenciado cada vez mais pelas famílias brasileiras. A pesquisa se utilizou, para dar seguimento ao assunto e fundamentação teórica, em grande parte por materiais bibliográficos, físicos e digitais, buscando as ideias dos principais autores renomados á respeito do tema abordado. Ainda, a metodologia utilizada foi o método dedutivo.

Palavras-chave: Guarda Compartilhada, Família, Pater Potestas, Guarda Unilateral.

\section{THE SHARED GUARD AND ITS RELEVANT ASPECTS}

\begin{abstract}
This work aimed to make considerations regarding shared custody, bringing the themes that interconnect and which are of paramount importance for the better understanding of the institute. Shared custody is a form of custody that was established in our legal system in order to ensure the parents' dual participation in the upbringing of children and the duties inherent to them. The realization of this study is perfectly adequate, whereas it is a fact that is increasingly experienced by Brazilian families. The research was used, to follow up on the subject and theoretical foundation, in great part by physical and digital bibliographical materials, searching the ideas of the main renowned authors regarding the subject approached. Still, the methodology used was the deductive method.
\end{abstract}

Keywords: Shared Guard, Family, Pater Potestas, Unilateral Guard.

\section{INTRODUÇÃO}

Nos últimos tempos, a estrutura familiar passou por várias mudanças, principalmente com uma maior participação da mulher no mercado de trabalho, e consequentemente uma maior contribuição financeira no orçamento domiciliar, e como necessário uma maior participação dos homens em tarefas onde anteriormente eram vistas como obrigação apenas da mulher.

Com essa divisão de tarefas pelos pais, destaca-se a obrigação de cuidar e zelar pelo físico e pelo psicológico dos filhos menores.

Juntamente com essa diversidade de possibilidades dentro do grupo familiar, é notório o crescente número de rompimento desses vínculos. Surgindo a partir de então, as consequências dessa ruptura, ocasionando a possibilidade de divisão das obrigações entre os pais em relação aos filhos. 
O instituto da Guarda Compartilhada surgiu no Brasil em nosso ordenamento jurídico, com a finalidade de proteger o interesse do menor, fazendo com que os pais dividam e participem igualitariamente na vida e nos deveres em relação aos filhos.

$\mathrm{O}$ instituto além de possibilitar o cumprimento dos direitos e deveres dos menores por seus pais igualmente, possibilita amenizar as consequências, principalmente psicológica, deixadas pela ruptura do vínculo conjugal.

O objetivo principal deste trabalho é demonstrar como se dá a origem e o instituto da guarda compartilhada e expressar os benefícios trazidos por ela.

\section{DA FAMÍLIA}

A família pode ser considerada a instituição mais antiga entre os seres humanos. Ainda, entre vários organismos jurídicos existentes, o direito de família é o que mais evolui com o tempo, e com as mudanças da sociedade os códigos vem acompanhando e protegendo essa evolução.

Ao longo da história, o conceito de família vem se refazendo. Na época da família grecoromana, a união entre o homem e a mulher se fazia pelo casamento, e a família se formava pelos descendentes daquela união. As famílias não se formavam pelo afeto, e sim pela convivência, para dar continuação a um ciclo.

A família patriarcal se caracterizava pela exclusividade que os pais, o marido, detinham em relação à esposa e os filhos. Nessa fase não existia o termo família, estando essas consideradas como patrimônio.

O homem tinha o poder familiar e era o chefe da casa, estando todo o resto do grupo familiar subordinado a ele, decidindo sobre a esposa, os filhos, e os bens dos filhos.

É considerado um marco na evolução, a entrada da Constituição Federal de 1988, que arrebatou as normas trazidas pelo Código Civil de 1916.

A nova estrutura familiar trazida pela constituição foi formada pelos princípios da igualdade, liberdade e dignidade da pessoa humana. Estes princípios ao serem implementados no direito de família, fez com que as famílias fossem formadas pelo amor recíproco dos companheiros.

O novo modelo de família trazido pelo Código Civil de 2002 deixou para traz as definições do Código de 1916. A família contemporânea é formada pelo amor, dando lugar a novas formas de constituição familiar, como a união estável, reconhecendo direitos iguais a todos os filhos, sejam frutos do casamento ou não, e ainda estabelecendo igualdade entre homem e mulher.

Assim se faz presente, cada vez que falamos em família, pensa-se logo na evolução que esta se criou, deixando de ser uma entidade formada apenas por homem e mulher, dando lugar a formação também por casais homoafetivos. Levando em conta, o amor e a afetividade.

A palavra família pode abranger vários significados dos quais nem mesmo a doutrina é capaz de defini-los concretamente.

A família é considerada uma entidade complexa, dada pelas suas mais diversas formas de se formar, e de evolução de seus costumes.

Uma melhor tradução de família é feita por Gomes (1998, p.33) quando considera família "o grupo fechado de pessoas, composto dos genitores e filhos, e para limitados efeitos, outros parentes, unificados pela convivência e comunhão de afetos, em uma só e mesma economia, sob a mesma direção".

Logo, se conclui que a família é formada por laços consanguíneos, jurídicos ou afetivos.

\section{DO PÁTRIO PODER AO PODER FAMILIAR}


O pátrio poder era constituído por um poder onde apenas o pai exercia as funções sobre os filhos e até mesmo sobre a mulher. Teve sua origem na Roma Antiga com o pater potestas. $\mathrm{O}$ pai, como chefe da família detinha total poder sobre atos e direitos dos filhos.

Deste modo, Rodrigues (2010, p.353) discorre sobre o pátrio poder como sendo um "direito absoluto e ilimitado conferido ao chefe da organização familiar sobre a pessoa dos filhos".

No direito romano, o homem exercia o papel mais importante da casa, e a mulher era totalmente submissa ao marido. Nessa época, mesmo que absurdo, a lei permitia até mesmo que o pai decidisse sobre a vida ou a morte de seus filhos.

Sabe-se que o Código Civil de 1916 adotava o Pátrio Poder, estando os filhos e a mãe sob o poder do pai.

Contudo, foi no século XX, que ocasionou as grandes transformações no meio familiar, redefinindo os papéis do pai e da mãe. Passando o pai de um papel autoritário e distante, á um pai presente e participativo. A mãe que antes era submissa ao marido, passou a ter seus direitos reconhecidos em igualdade de condições com o homem. O filho, antes podendo ser abandonado ou escolhido para morrer, passou a ocupar o principal papel entre essa relação, passou a ser o centro de atenção e cuidado. Assim, Levy (2008, p.09) ressalta: “ontem, o pátrio poder, hoje, o dever parental".

Destarte, o Código vigente trouxe para o ordenamento jurídico brasileiro a ideia de poder familiar, deixando para traz a ideia primária de cuidados e deveres, fazendo com que o filho fosse o centro de atenção e cuidado, dando á ele o direito de ser amado e protegido pelos pais.

Hoje, o principal papel do poder familiar é defender os direitos dos filhos e da família. E não apenas o interesse apenas do homem, como no pátrio poder.

A distinção dos institutos pode ser observada, conforme Beviláqua (1960, p.279) diz que o "pátrio poder é o complexo dos direitos que a lei confere ao pai, sobre a pessoa e os bens dos filhos". E Rodrigues (2008, p.358) conceitua poder familiar como: "conjunto de direitos e deveres atribuídos aos pais, em relação à pessoa e aos bens dos filhos não emancipados, tendo em vista a proteção destes".

A partir destas informações conclui-se então, que o poder familiar é o conjunto de prerrogativas atribuídas aos pais para a criação e proteção dos filhos menores de 18 anos e de seus bens.

\section{DA GUARDA}

A guarda representa um poder e uma obrigação que o pai e a mãe exercem sobre o filho menor. A guarda natural é aquela que detém o pai e mãe logo quando nasce a criança, quando se faz o registro do filho. $O$ poder familiar esta inserido neste momento.

Para Monteiro e Silva (2011, p.394), "a guarda é um direito e ao mesmo tempo um dever dos genitores de terem seus filhos sob seus cuidados e responsabilidade, cuidando de sua alimentação, saúde, educação, moradia etc.".

Na família constituída pelo casamento ou por união estável, é agregada a guarda comum dos pais, onde vivam sob o mesmo teto e dividam então os deveres inerentes aos filhos.

Mas, então, tem-se a figura da guarda unilateral ou compartilhada, quando os pais não moram juntos, seja por separação, ou simplesmente, por nunca terem vivido sob o mesmo teto.

Nas palavras de Ramos (2016, p. 64):

A guarda unilateral é aquela atribuída a um só dos genitores ou a alguém que o substitua. E a guarda compartilhada é a responsabilização conjunta e o exercício de direitos e deveres do pai e da mãe que não vivam sob o mesmo teto, concernentes ao poder familiar dos filhos comuns (art. 1.583 do Código Civil). 
De um modo geral, independente do tipo da guarda, seja ela comum, unilateral e/ou compartilhada, os pais têm em igualdade de condições, deveres que precisam ser cumpridos em relação aos filhos. O dever de cuidar, zelar, educar e sustentar o menor.

Ainda segundo Ramos (2016, p.65):

A guarda, examinada sob a perspectiva do poder familiar, é tanto um dever como um direito dos pais: dever, pois incumbe aos pais criar e educar os filhos, sob pena de estarem deixando o filho em abandono; direito no sentido de os pais participarem do crescimento dos filhos, orientá-los e educá-los, exigindo-lhes obediência, podendo retê-los no lar, conservandoos junto a si, sendo indispensável à guarda para que possa ser exercida a vigilância, uma vez que o genitor é civilmente responsável pelos atos do filho.

Cabendo dessa maneira, o poder familiar atribuído aos pais e não somente a um só deles. Entendendo-se que a guarda caberá ao pai e a mãe como uma obrigação, um dever.

\section{A GUARDA COMPARTILHADA E SEUS BENEFÍCIOS}

Ao ser promulgado, o Código Civil de 2002 não previa a guarda compartilhada, embora a doutrina já se posicionasse a respeito admitindo o compartilhamento da guarda.

Entretanto, a Lei $\mathrm{n} 011.698$, de 13 de junho 2008, alterou a respeito do que trazia os artigos 1.583 e 1.584 do referido Código. Ademais, a Lei 13.058, de 22 de dezembro de 2014, alterou novamente os artigos 1.583, 1.584, 1.585 e 1.634 do Código Civil, onde estabeleceu o significado da expressão "guarda compartilhada".

A guarda compartilhada pode ser adotada por consenso das partes ou por decisão do juiz, quando este entender. A regra é de que na falta de acordo entre os pais, a guarda seja compartilhada, conforme estabelece o artigo 1.584, parágrafo 20 do C.C

O que prevalece nessa modalidade de guarda é o convívio da criança com seus dois pais. Apesar da ruptura da relação destes, sobrepõe à existência do amor que carregam pelos filhos e que não serão interferidos pelo fim da relação que uniram um dia seus pais.

Aqui, o pai e mãe têm os mesmos direitos e deveres em relação aos filhos. Ambos os pais decidirão sobre questões inerentes ao poder familiar e dividirão o tempo de companhia dos filhos, alternando momento de convivência, desde que isso não seja nocivo ao bem estar do menor.

Em relação ao dever de educar o menor, é uma obrigação conjunta dos pais. Cabendo a eles dividirem esse dever da melhor maneira possível. Como se trata de uma obrigação, não poderá se dispor de tal.

Ainda, a guarda compartilhada não tem um modelo padrão. Ela é um instituto voltado para o interesse da criança e do adolescente, e é um instituto que permite a sua formatação pelos pais com o auxilio da justiça, sempre voltado para o melhor interesse da criança.

O poder familiar, como sendo o conjunto de direitos e deveres dos pais em relação aos filhos, se encaixa perfeitamente dentro da guarda compartilhada. Uma vez que mesmo sendo os pais separados, eles detêm igualitariamente poderes e deveres sobre a vida do menor, decidindo em conjunto tudo o que se refere à vida deste.

Importante considerar que a guarda compartilhada, também é passível de reversão. Se um dia a guarda se revelar melhor com a companhia da mãe, a esta deverá ser considerada e passada a guarda para unilateral.

A guarda compartilhada surgiu com o concreto interesse em trazer benefícios aos filhos e aos pais separados. Esta modalidade de guarda tem a real intenção de manter os vínculos entre pais e filhos, mesmo após a ruptura do laço conjugal.

Como se trata de filhos, se trata de amor, se tratando de amor evidencia-se o prestígio de 
poder os dois pais participarem da vida dos filhos, em momentos de lazer, em momentos de decisões importantes, e no dia a dia.

Os filhos são considerados os maiores prestigiados nesta modalidade. Uma vez que não são culpados pela decisão de separação dos pais, estando então em total direito de ter uma criação harmônica e de amor entre eles.

Para Levy (2008, p.136):

O caminho da conjugalidade para a co-parentalidade harmoniosa nem sempre é suave, nem sempre é possível. Entretanto, embora difícil, este caminho deve ser trilhado a bem dos filhos, que não podem ser vitimas de pais despreparados para o exercício de tão nobre função.

A guarda compartilhada pode ser considerada como um minimizador dos efeitos da separação dos pais. Quando se tem o término de uma união estável ou a separação efetiva dos pais fica comprometido a referencia do núcleo familiar, do pai e da mãe conviverem o dia inteiro e todo dia com seus filhos.

A guarda compartilhada garante que a referência do pai e da mãe se mantenha presente perante a criança.

A certeza de que os vínculos com os pais serão mantidos, ainda que estes não mais compartilhem o mesmo lar, é de extrema importância para o menor, pois dá a esta criança, a segurança de que continuará sendo amado, e protegido pelos pais, mesmo após o fim da relação.

Importante destacar que o que se acaba é o laço conjugal e não a autoridade parental dos pais para com os filhos. Então, mais uma vez a guarda compartilhada se faz necessária no sentido de manter os laços parentais.

Nas palavras de Akel (2010, p.104):

O pressuposto maior desse novo modelo é a permanência dos laços que uniam pais e filhos antes da ruptura do relacionamento conjugal. A premissa sobre a qual se constrói esta guarda é a de que o desentendimento entre os pais não pode atingir o relacionamento destes com os filhos e que é preciso e sadio que estes sejam educados por ambos os pais e não só por um deles, conforme ocorre em milhares de relações familiares.

Continua Akel (2010, p.106):

O exercício compartilhado da guarda, dentre outras vantagens a serem apontadas, preserva os vínculos afetivos, uma vez que o pai não perde o filho, nem este aquele, ressaltando, por mais uma vez, que a conjugalidade pode se romper, mas nunca a parentalidade.

Um ponto importante para destacar é que o modelo de guarda compartilhada impede a angustia, o sofrimento e o constrangimento do menor de permanecer com apenas um dos pais. Sabendo ele que poderá estar com os dois pais, quando quiser e que somente não moraram na mesma casa, com certeza é motivo de alívio e alegria para a criança.

Outro aspecto importante é de que, a guarda compartilhada, faz com que os pais dividam tudo no que diz respeito aos filhos. Deste modo, faz com que nenhum se sinta sobrecarregado, e os dois poderão exercer o papel de pais presentes, não restando sentimento de culpa a algum deles, pelo motivo de não poder participar ativamente na vida do filho.

\section{CONCLUSÃO}


Conforme pode ser observado, este presente trabalho abordou a guarda compartilhada, juntamente com suas derivações.

Ao longo dos anos, a família se modificou. O que antes na época do patriarcado era papel apenas do pai, hoje com o espaço que a mulher conquistou, passou a ser papel de ambos os pais, o poder familiar.

Com a evolução da família, se fez presente analisar que as relações conjugais se mostraram muitas vezes frustradas, fazendo que isso refletisse sobre os filhos do casal.

A guarda compartilhada entra em nosso ordenamento jurídico com o intuito de acabar com as discussões a respeito da vida dos filhos e para fazer com que o menor possa gozar inteiramente do direito de permanecer com o pai e com a mãe.

A melhor interpretação cabe ao passo de que o juiz deverá impor o regime de guarda compartilhada, sempre prevalecendo o principio do melhor interesse da criança. Hoje ela é considerada regra. Onde só se passará á um novo regime de guarda quando um dos pais não tiver interesse no compartilhamento da guarda, ou se mostrar inapto para tal.

É evidente que esta modalidade de guarda veio para trazer benefícios para ambas às partes, pai e mãe, e obviamente também para o menor. Uma vez que estando os pais em igualdades de direitos sobre seus filhos, e estando estes inteiramente amparados pelos pais, evitase o desgaste emocional da criança.

\section{REFERÊNCIAS}

AKEL, Ana Carolina Silveira. Guarda Compartilhada: um avanço para a família. 2. ed., 2. reimpr. São Paulo: Atlas, 2010.

ALMEIDA Renata Barbosa de; RODRIGUES JUNIOR, Walsir Edson. Direito Civil: famílias. 2. ed. São Paulo: Atlas, 2012.

BARRETO, Luciano Silva. Evolução histórica e legislativa da família. Escola da Magistratura do Estado do Rio de Janeiro. Disponível em: <http://www.emerj.tjrj.jus.br/serieaperfeicoamentodemagistrados/paginas/series/13/volumel/10 anosdocodigocivil_205.pdf>. Acesso em: 18 abr. 2017.

BEVILÁQUA, Clóvis. Código Civil dos Estados Unidos do Brasil comentado. 12. ed. atual. Rio de Janeiro: Francisco Alves, 1960. v. 2.

BRASIL. Constituição da República Federativa do Brasil de 1988. Brasília: DF, Senado, 1988.

. Lei no. 3.071, de 1 de janeiro de 1916. Código Civil.

. Lei no. 10.406, 10 de janeiro de 2002 - Código Civil.

. Lei no. 11.698, de 13 de junho de 2008. Altera os arts. 1.583 e 1.584 da Lei no. 10.406, de 10 de janeiro de 2002 - Código Civil, para instituir e disciplinar a guarda compartilhada.

. Lei $n=13.058$, de 22 de dezembro de 2014. Altera os arts. 1.583, 1.584, 1.585 e 1.634 da Lei no 10.406, de 10 de janeiro de 2002 (Código Civil), para estabelecer o significado da expressão "guarda compartilhada" e dispor sobre sua aplicação. 
GOMES, Orlando. Direito de Família. 11. ed. Rio de Janeiro: Forense, 1998.

LEVY, Fernanda Rocha Lourenço. Guarda de filhos: os conflitos no exercício do poder familiar. São Paulo: Atlas, 2008.

MONTEIRO, Washington de Barros; SILVA, Regina Beatriz Tavares. Direito de Família. 41. ed. São Paulo: Saraiva, 2011.

MOURA, Mário Aguiar. Guarda de filho menor. Ajuris 19, p. 14- 33, Porto Alegre, jul./1980.

NADER, Paulo. Curso de direito civil: direito de família. 7. ed. Rio de Janeiro: Forense, 2016. v.5.

RAMOS, Patrícia Pimentel de Oliveira Chambers Poder familiar e guarda compartilhada: novos paradigmas do direito de família. 2. ed. São Paulo: Saraiva, 2016.

RODRIGUES, Silvio. Direito de família. São Paulo: Saraiva. 1991. v. 6.

SANTOS NETO, José Antônio de Paula. Do Pátrio Poder. São Paulo: Revista dos Tribunais, 1994

VENOSA, Silvio de Salvo. Direito Civil: direito de família. v. 6., 13 ed. São Paulo: Atlas, 2013. 